\title{
Review of Earned Value Management Extensions
}

\author{
${ }^{1}$ Chitti Babu Kapuganti, ${ }^{2}$ Balaji K. V.G.D, ${ }^{3}$ T.Santhosh Kumar, ${ }^{4}$ S.Eswar Rao \\ ${ }^{1,3}$ Assistant Profesor, GITAM School Of Architecture, GITAM(Deemed to be University), Visakhapatnam, India 530045 \\ ${ }^{2}$ Professor, Department of Civil Engineering, GITAM(Deemed to be University), Visakhapatnam, India 530045 \\ ${ }^{4}$ Assistant Professor,Department of Civil Engineering,GITAM(Deemed to be University), Visakhapatnam, India 530045 \\ * corresponding author: santhosh.civil2007@gmail.com
}

\begin{abstract}
To successful project completion, the project management team requires to monitor and control the actual work performed and update informationat each instant of the lifecycle. Earned Value Management $(E V M)$ is a familiar method that serves best for this purpose.It integrates cost performance and schedule performance into a single window toforecast both expected cost and time at completion. These forecasts help the project management team to monitor and control any critical deviations. Forecasting activity parameters is essential step in construction project management thus the feedback from Estimates at Completion maximize probability of getting schedule, quality, cost as per project plan by highlighting possible need of corrective actions. Many EVM extensions have been developed in recent years to improve forecasting accuracy. This paper reviews various duration forecasting extensions of EVM.
\end{abstract}

Key words: Bayesian EVM, Duration Forecast,Earned Value Management, Earned Duration Management, Earned Schedule, Fuzzy EVM, Grey EVM, Planned Value Method, Schedule Forecast.

\section{INTRODUCTION}

In the early 1980s, Earned Value Management (EVM) have been introduced by the United States of America Department of Defense (DoD). EVM is mainly developed as a tool to integrate scope with cost, duration of the government projects. Later, its applicability has widespread into private sector projects. U.S. DoD defines EVM as "an integrated set of policies, procedures, and practices to support program and project management as a decision enhancing tool and a critical component of risk management"[1].EVM defines cost and schedule parameters to monitor and control projects. EVM helps in project status measurement, effective resource management, project change management, predict the completion cost, and duration.

EVM isa commonly used structured process to control all sizes of projects ranging from small to large. EVM measures and communicates the current performance of the project. EVM involves defining the scope of work; authorization of scope; development of baseline; performance measurement; analysis of variance; report corrective action and frequent incorporation of changes[2]. EVM requires an elaborated bottom-up performance and measurements against the baseline plan. Rased on the current actual nerformance F.VM foresasts

final expected results. These results may be either Estimate at Completion (EAC) or Estimate Duration at Completion $\left(\mathrm{EAC}_{\mathrm{t}}\right)$. These forecasts help the project management team to monitor and control project at every periodical interval.

The motivation for paper comes from the fact that a continuous stream of publications on duration forecasting extensions of EVM has been published in academic literature, it appears to be a lack of attention paid to the systematic review of existing literature.

The outline of this paper can be summarized as follows:Section 2provides the background of traditional EVM method. Section3covers overview of Deterministic extensions of EVM. Probabilistic Extensions of EVMprovided in Section4. Section 5 gives overview of Fuzzy Extensions of EVM. The paper ends with the conclusion.

\section{TRADITIONAL EARNED VALUE MANAGEMENT (EVM)}

EVM is first introduced by U.S. DoD for monitoring cost and schedule performances in the Minuteman missile program. After that,the U.S. government adopted this procedure to manage its leading development projects[3]. It became so successful and well-spread in other industries. In recent years, EVM becomes one of the best project monitoring and controlling tools. EVM is well recognized by various project management organizations[1].

EVM is just a collection of project management best practices. It is a project management tool that integrates cost, schedule, and scope. EVM provides many benefits to the organizations, some include, cost and duration forecasts, objective accomplishment measurement, deviations in the scope, and early warnings of cost overrun and delays[4].

\begin{abstract}
EVM terminology can be classified into two categories: key parameters and EVM measures. The process starts with evaluating key parameters - Planned Value (PV), Earned Value $(E V)$, and Actual Cost (AC). These key parameters are defined
\end{abstract}

in

Table 1. Later, EVM measures can be assessed by using key parameters. Abbreviations and formulas of EVM Measures are mentioned in 
Table 1:EVM Parameters

\begin{tabular}{|c|l|}
\hline Parameter & Definition \\
\hline PV & $\begin{array}{l}\text { Planned value, the cumulative cost of } \\
\text { work planned at data date }\end{array}$ \\
\hline EV & $\begin{array}{l}\text { Earned value, the cumulative cost of } \\
\text { work earned at data date }\end{array}$ \\
\hline AC & $\begin{array}{l}\text { Actual cost, the cumulative cost of } \\
\text { work incurred at data date }\end{array}$ \\
\hline SAC & $\begin{array}{l}\text { Schedule at completion, the total } \\
\text { planned duration of the project }\end{array}$ \\
\hline BAC & $\begin{array}{l}\text { Budget at completion, the Budgeted } \\
\text { total cost of the project }\end{array}$ \\
\hline AT & \begin{tabular}{l} 
Actual time. Point of time data noted. \\
\hline
\end{tabular}
\end{tabular}

Table 2:EVM Measures

\begin{tabular}{|c|c|c|}
\hline Metric & Formula & Definition \\
\hline$C V$ & $\mathrm{EV}-\mathrm{AC}$ & $\begin{array}{c}\text { Cost variance, Budgetary } \\
\text { conformance of work } \\
\text { performed }\end{array}$ \\
\hline$S V$ & $\mathrm{EV}-\mathrm{PV}$ & $\begin{array}{c}\text { Schedule variance, } \\
\text { schedule conformance of } \\
\text { work performed }\end{array}$ \\
\hline$C P I$ & $\frac{E V}{A C}$ & Cost performance index \\
\hline$S P I$ & $\frac{E V}{P V}$ & $\begin{array}{l}\text { Schedule Performance } \\
\text { Index }\end{array}$ \\
\hline$E A C$ & $\mathrm{AC}+\frac{B A C-E V}{C P I}$ & Estimate at completion \\
\hline$E A C_{t}$ & $\frac{S A C}{S P I}$ & $\begin{array}{l}\text { Estimated duration at } \\
\text { completion. }\end{array}$ \\
\hline
\end{tabular}

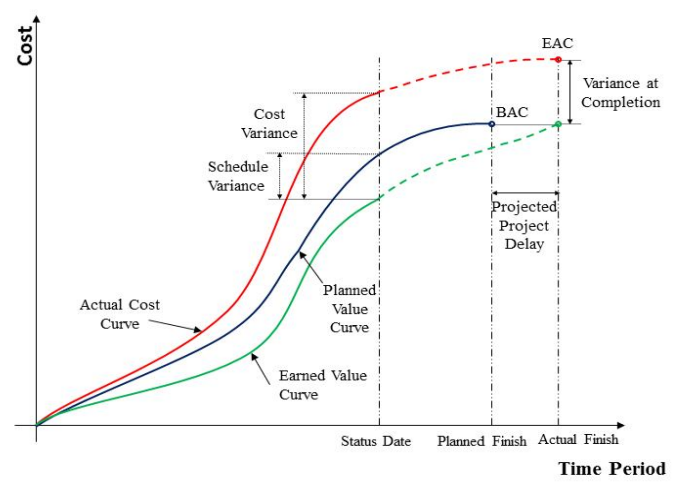

Figure 1: Earned Value Management

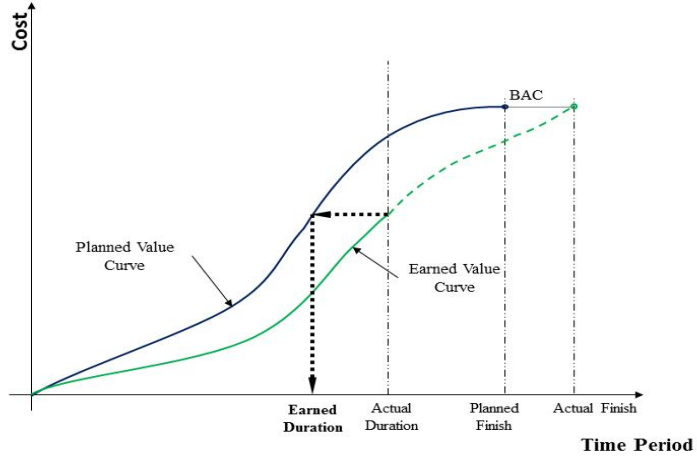

Figure 2: Planned Value Method

EVM indices indicate project performance efficiency. Project managers can examine the project progress with the help of cost variance and schedule variance. CPI and SPI depict the current status of the project and forecasts the cost and duration at completion. More precisely, $\mathrm{SV}>0, S P I>1(\mathrm{SV}<0, S P I<1) \quad$ indicates ahead (behind) of schedule and $\mathrm{CV}<0, C P I<1(\mathrm{CV}>$ $0, C P I>1$ ) indicates over (under) budget.These variances can suggest mangers enforce any corrective actions required to reach the project objectives beforehand as shown in Figure 1

Initially, the schedule parameters are seeming to establish a trend, but at the end of the project SPI closes to one and SV closes to zero. This unconventional behavior can be observed in all projects utilizes EVM. This irregular behavior of the schedule indicators with its accompanying misunderstandings and misinterpretations deteriorates the initiative to broaden acceptance and applicability of EVM[5].

Many researchers argue that EVM calculates schedule properties in monitory termsand gives erroneously estimated duration at completion. This motivates researchers to develop extensions for the accurate estimating duration at completion.Extensions can be classified as deterministic approaches, probabilistic approaches, and fuzzy approaches.

\section{OVERVIEW OF EXTENSIONS OF EVM}

DETERMINISTIC

Some managers give more importance to cost compared to time. Time is interlinked with cost but, no mathematical relationship defined between them. Time is also as important as cost. So, we cannot measure the correct schedule performance index using EVM[6]. At some point in time, Managers will feel that they had a wrong belief about schedule performance indicators'. This point onwards they cannot depend on these EVM indicators.

\subsection{Planned Value Method (PVM)}

[7] have introduced $E A C_{t}$ based on Planned value rate ( $P V$ Rate), Time variance $(T V)$, and Time variance at completion $(T V A C)$. Planned value rate indicates the planned cost per unit time period, PV Rate $=B A C / S A C$. Time variance represents burn rate, represents the actual amount spend for a unit time period, $\mathrm{TV}=S V / P V$ Rate. TVAC indicates the variance of time at completion, the difference between $S A C$ and $E A C_{t}$. 
PVM classifies current status of a project into six categories and precisely given $E A C_{t}$ formulafor each category. This forecasting method improves the accuracy of $E A C_{t}$ by considering both the present status and predicted future performance. Even though six categories of the project performance were considered, all estimates are based on the monitory terms.

\subsection{Earned Schedule Method (ESM)}

[8]introduced the Earned Schedule method which measures true schedule performance by calculating the time coordinate of $E V$ curve. Earned Schedule method transforms EV at any given point into its equivalent duration needed to accomplish corresponding planned value. The earned schedule method identifies the earned value which should be achieved for specified planed value. This method is an extension of EVM, monitors the schedule performance in terms of time units.

The earned schedule is the time at which current earned value needs to achieve in the base plan. It is calculated as $E S_{t}=t+\left\{(E V-P V) /\left(P V_{t+1}-P V_{t}\right)\right\}$, where $\mathrm{t}$ is integer time period for which $E V \geq$ $P V_{t}$. Schedule performance Index with respective time is given as $S P I_{t}=E S_{t} / A D$ If $S P I_{t}>1$, the project is ahead of schedule and $S P I_{t}<1$, the project is behind the schedule as shown in Figure 3.

[9]defined Earned value as the sum of earned value up to earned schedule and earned value due to rework. By using the earned schedule, schedule adherence can be calculated as $P=\sum E V_{k} / \sum P V_{k}$, where $\mathrm{EV}_{\mathrm{k}}$ indicates earned value of tasks up to earned schedule and $\mathrm{PV}_{\mathrm{k}}$ indicates earned value of tasks up to earned schedule. Schedule adherence provides the capability to analyze the schedule quality, process constraints that may lead to future rework[10].

\subsection{Earned Duration Method}

Earned value management has been introduced as a cost measuring technique. Other extensions like planned value method and earned schedule method also use costrelated indices to measure time. This correlation is proven to be misleading project managers as progress reaches the end of the project. To eradicate this vagueness [11] have decoupled cost and schedule by introducingnovel Earned Duration Method. EDM increased emphasis on schedule perspective.

EDM monitors project schedule based on total planned duration (TPD), Total Actual Duration (TAD) and Total Earned Duration (TED). many advantages have been observed in schedule monitoring based on duration perspective as shown in Figure 4. Earned duration $\left(E D_{t}\right)$ on status date is givenas $t+\left(\frac{T E D-T P D_{t}}{T P D_{t+1}-T P D_{t}}\right) \times 1(C U)$

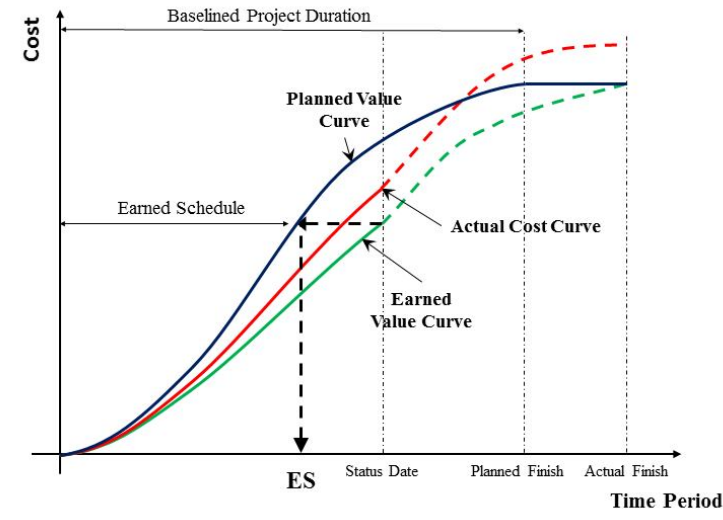

Figure 3: Earned Schedule Method

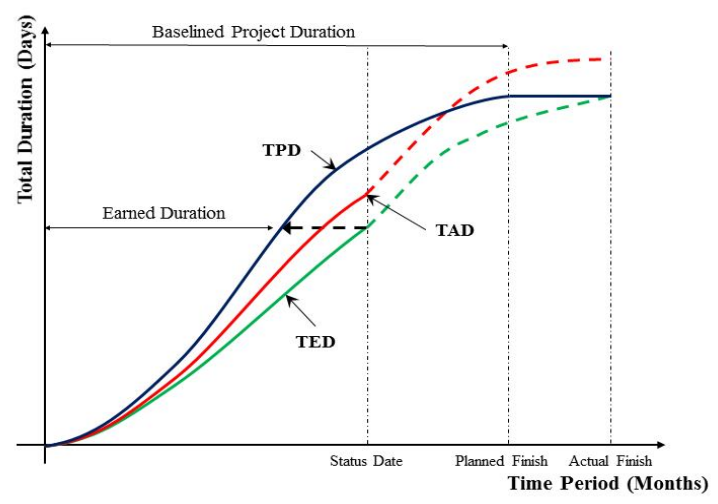

Figure 4:Earned Duration Method

where CU stands for calendar unit, $\mathrm{t}$ is a calendar unit such that $T P D_{t} \leq T E D$ and $T P D_{t+1}>T E D$. By using $E D_{t}$, schedule performance indices can be calculated as Earned Duration Index $(E D I)=\frac{T E D}{T P D}$ and Duration Performance Index $(D P I)=\frac{E D_{t}}{A D}$. The values of $E D I>$ $1(E D I<1)$ indicates accomplished work is greater (lesser) than the work planned. If $D P I>1$, the project is ahead of schedule and $D P I<1$, the project is behind the schedule.

\section{OVERVIEW OF PROBABILISTIC EXTENSIONS OF EVM}

Despite wide acceptance and extensive use of EVM forecasting approaches, many researchers criticized that outcome of EVM is deterministic due to its point estimates. Due to this reason, researchers proposed new techniques by coupling EVM with some probability theories[12].

Probabilistic methods are based on the correlation between the past performance of the project and the future performance of the project. They simulate real-life situations for a large number of cases and analyze the result based upper and lower limits of the estimated range.

Probabilistic approaches enable users to determine a more accurate at-completion budget and schedule. These approaches also evaluate performance improvement of proposed corrective actions. 
Chitti Babu Kapuganti et al., International Journal of Emerging Trends in Engineering Research, 8(10), October 2020, 7540 - 7547

\subsection{EVM using Stochastic S-Curves}

[13] proposed integration of Stochastic S-Curves with EVM. Progress based Stochastic S-Curves provides probabilistic distributions for the budget and schedule estimates at completion at every tracking point in the project execution phase. In this model, SS-Curves are obtained by simulating total work progress, Estimated Cost at Completion and Estimated Duration at completion as shown in Figure 5.

At every tracking point, work progress should be measured. Cost variance $(\mathrm{CV})$ at that point is variation of expected budgeted cost of work progressed $\left(\mu_{\mathrm{BCWP}}\right)$ from actual cost of work progressed (ACWP). Time variance at that point is variation of expected time for work progressed $\left(\mu_{\text {PDWP }}\right)$ from elapsed time for work progressed (ETWP).

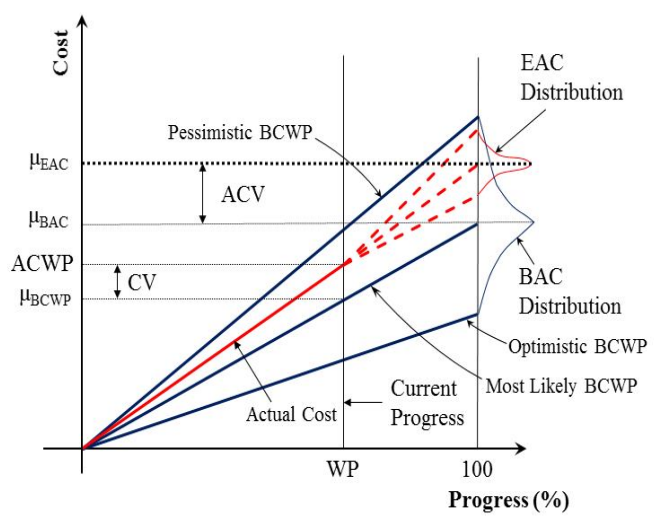

Figure 5: EVM using Stochastic S-Curves - Cost

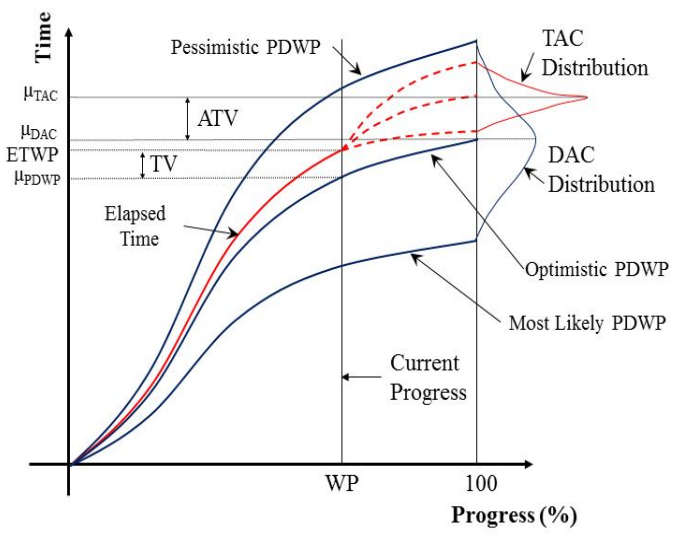

Figure 6: EVM using Stochastic S-Curves - Time

Cost variance at completion (ACV) is difference between expected budgeted cost at completion $\left(\mu_{\mathrm{BAC}}\right)$ and expected cost at completion $\left(\mu_{\mathrm{EAC}}\right)$. Time variance at completion is difference between expected duration at completion $\left(\mu_{\mathrm{DAC}}\right)$ and expected elapsed time $\left(\mu_{\mathrm{TAC}}\right)$ as shown in Figure 6. Estimated cost and duration at completion can be determined based on two cases. (1) Future performance of activities is as estimated as per the plan. (2) Future performance of activities is expected to depend on previously performed activities. 2 cases are explained in Table 3.
Table 3: At completion Cost and Durationbased on SS curves

\begin{tabular}{|c|c|}
\hline Case & Metric \\
\hline \multirow{2}{*}{ Case - I } & $E A C=A C W P+(B A C-B C W P)$ \\
\cline { 2 - 2 } & $T A C=E T W P+(D A C-P D W P)$ \\
\hline \multirow{2}{*}{ Case - II } & $E A C=\frac{B A C}{C P I}$ \\
\cline { 2 - 2 } & $T A C=\frac{D A C}{S P I}$ \\
\hline
\end{tabular}

\subsection{Bayesian Approach to EVM}

After starting the project, reliable forecasts are needed because a detailed plan may not incorporate inherent risks that influence the actual project performance. As time progresses the effectiveness of corrective actions decreases and information accuracy regarding activities increases. Bayesian Approach combines EVM with experts' judgments and past performance data to determine future CPI and SPI. Logarithm of $\mathrm{CPI}_{\mathrm{f}}$ and $\mathrm{SPI}_{\mathrm{tf}}$ follows Gaussian distribution with mean $(\mu)$ and standard deviation $(\sigma)$.

Bayesian approach best suits for non-repeating processes like construction projects which are having rapid changes in available information. Bayesian approach assumes log normal probability distribution function as (1). Prior distributions for mean and variance is given in (2) and (3) respectively.

$$
\begin{aligned}
& f\left(x \mid \mu, \sigma^{2}\right)=\frac{1}{\sqrt{2 \pi} \sigma x} e^{-\frac{\{\ln x-\mu\}^{2}}{2 \sigma^{2}}} \\
& f(\mu) \sim N\left[\theta, \xi^{2}\right]=\frac{1}{\sqrt{2 \pi \xi}} e^{-\frac{(\mu-\theta)^{2}}{2 \sigma^{2}}} \\
& f\left(\sigma^{2}\right) \sim \operatorname{IVN} G(\alpha, \beta)=\frac{\beta^{\alpha}}{\Gamma(\alpha) \sigma^{2(\alpha+1)}} e^{-\frac{\beta}{2 \sigma^{2}}}
\end{aligned}
$$

To forecast future value, this approach includes experts' opinion into prior distribution. To minimize cognitive biases from human thinking about probability. Experts need to provide their opinions about three main characteristics of the project: Final average cost of the project, Final average completion date and Overall uncertainty level of the project.Mean $(\theta)$ and standard deviation $(\xi)$ from experts' data are given in (4) and (5) respectively.

$$
\begin{aligned}
& \theta=\frac{\sum_{i=1}^{N} \mu_{i}}{N} \\
& \xi=\sqrt{\frac{\sum_{i=1}^{N}\left[\mu_{i}-\mu\right]^{2}}{N-1}} \\
& \text { Hyper parameters } \alpha \text { and } \beta \text { are determined based on the } \\
& \quad \text { uncertainty level from the exerts' opinion as in }
\end{aligned}
$$

Table 4. Posterior distributionof mean and standard deviation as in (6)and (7) is framed based on prior distribution and experts' opinion. 
Table 4:Hyper Parameters values based on Uncertainty level

\begin{tabular}{|c|c|c|}
\hline $\begin{array}{c}\text { Uncertainty } \\
\text { Level }\end{array}$ & $\boldsymbol{\alpha}$ & $\boldsymbol{\beta}$ \\
\hline 1-Low & 0 & 0.3 \\
\hline 2-Medium & 0.1 & 0.3 \\
\hline 3 - High & 0.3 & 0.5 \\
\hline
\end{tabular}

$f\left(\mu \mid \sigma^{2}, x\right) \sim N\left(\frac{\left[\xi^{2} \cdot \sum_{i=1}^{n} \ln x_{i}+\sigma^{2} \theta\right]}{\xi^{2}+\sigma^{2}},\left[\frac{\sigma \cdot \xi}{\sqrt{\left(\xi^{2}+\sigma^{2}\right)}}\right]^{2}\right)$

Error! Bookmark not defined.

$f\left(\sigma^{2} \mid \mu, x\right) \sim \operatorname{IVNG}\left(\frac{n}{2}+\alpha, \frac{1}{2} \cdot \sum_{i=1}^{n}\left(\ln \left(x_{i}\right)-\mu^{2}\right)+\right.$ $\beta)$ Error! Bookmark not defined.

After determining posterior distributions of mean and $\mathrm{SD}$, Monte Carlo Simulations are applied to determine posterior predictive densities of $\mathrm{CPI}_{\mathrm{f}}$ and $\mathrm{SPI}_{\mathrm{tf}}$. By using $\mathrm{CPI}_{\mathrm{f}}$ and $\mathrm{SPI}_{\mathrm{tf}}$, EAC and TAC can be determined as normal EVM methodology.

Bayesian approach based on experts' opinion permits inclusion of subjective judgement in a propermanner leading to accurate estimate of forecasting parameters within EVM framework.

\subsection{EVM with Bayesian Beta S- Curve Method (BBM)}

For ongoing projects, manager needed a consistent cost and time scheduleswith inherit risks and uncertainties in actual project performance. These schedules help managers to forecast estimates at completion. Traditional EVM is deterministic and lacks in incorporating risks and uncertainties to deliver confidence limits on predictions. Toimprove accuracy of project forecasts[12]presented a new model based on Bayesian Inference and beta distribution curve fitting technique.

To apply BBM, project manager needs to have the prior performance information and the actual project performance data. BBM quantifies prior performance data from historical data, project plans and personal judgements. It forecasts project duration by relaying only on summary level project performance information and updates the predicted project completion established on new performance information.BBM includes two steps: Generating prior distributions of Beta $\mathrm{S}$ curve parameters and Updating Parameters with Bayesian distribution.

Generating prior distributionsof Beta $S$ curve parametersbased on type of prior information and the decision maker'sconfidence level. They include duration parameter $(\mathrm{T})$ and shape parameters $(\alpha$, $\mathrm{m})$.Priors may be either informative or noninformative. Informative priors are consideredwhen prior performance information is appropriate to actual performance.Noninformative priors are considered when prior performance information is inappropriateto actual performance.

Whenever new information available, shape parameters need be revised and Bayesian updating need to do for betaS-curve function. Let parameter $\operatorname{set} \Theta \approx\{\alpha, m, T\}$ then prior probability distribution of parameter set is represented as in (8). After starting of the project, periodical actual project progress is represented as series of discrete variable $D$ for cumulative work progress $\left(w_{i}\right)$ reported at time $\left(t_{i}\right)$ in $\mathrm{N}$ tracking points is given in (9)

$$
\begin{aligned}
& p(\Theta)=p(\alpha) \times p(m) \times p(T) \\
& D:\left(w_{i}, t_{i}\right), i=1,2, \ldots, N
\end{aligned}
$$

Likelihood of data conditional on the parameters chosen is calculated based on difference between the actual performance reporting times and the planned times established by the betaS-curve parameters $T\left(w_{i} \mid \Theta\right)$. The objective is to obtain a set of parameters that produce the deviations normally distributed with zero mean and standard deviation $\sigma$. The likelihood of the data is calculated as product of likelihood of each observation as in (10). To adjust the sensitivity of predictions to the actual data reported, the estimator selects the value of $\sigma$.

$$
p(D \mid \Theta)=\prod_{i=1}^{N}\left(\frac{1}{\sqrt{2 \pi} \sigma}\right) e^{\left[-\frac{1}{2}\left(\frac{t_{i}-T\left(w_{i} \mid \Theta\right)}{\sigma}\right)^{2}\right]}
$$

The marginal distribution of observed actual progress is given in (11) and joint probability distribution of parameters and data is shown in (12).

$$
\begin{aligned}
& p(\Theta)=\int p(D, \Theta) d \Theta \\
& p(D, \Theta)=p(D \mid \Theta) p(\Theta)
\end{aligned}
$$

Each model parameter posterior marginal distribution obtained from Bayesian updating the observed data.The goal of the Bayesian updating is to obtain a revised orposterior marginal distribution of each model parameter conditional on the observed data. The marginal posterior distribution of parameter can be derived by integrating joint parameter distribution of the observed data with respective to $\Theta^{-\alpha}=\{m, T\}$ is given in (13).

$$
p(\alpha \mid D)=\int p(\Theta \mid D) d \Theta^{-\alpha}
$$

For computing the posterior distributions requires multifold integration of parameters used in analysis.By using BBM, estimator does not require any detailed information about the progress of individual activities or updated durations of futureactivities.

\section{OVERVIEW OF FUZZY EXTENSIONS OF EVM}

Earned value management technique assists project manager in measure and evaluate project progress and asses the project performance by forecasting completion cost and time with help of actual parameters at every tracking points[14]. In reality the data regarding the activities come fromestimator's judgment so they carry some degree of uncertainty.

The actual project performance measurement is in subjective in nature and develops uncertainty in 
Chitti Babu Kapuganti et al., International Journal of Emerging Trends in Engineering Research, 8(10), October 2020, 7540 - 7547

forecasts. Usage of linguistic terms in estimating percentage completion of each activitycan avoid these problems. Fuzzy extensions of EVM eliminates such problems.

\subsection{Fuzzy approach for EVM}

In many situations, the total amount of work required for performing the activities are un-known and uncertain. EVM gives deterministic forecasts by not integrating uncertainty into its calculations. This issue can conquer by way of incorporating some fuzzy theories into EVM methodology[15].

First step in Fuzzyapproach is converting the real progress of activities fromlinguistic termsinto fuzzy numbers by applying fuzzy principals. Typically, the project manager performs this transformation in accordance withhis knowledge and experience and with activity parameters.From various fuzzy number types,trapezoidal fuzzy numbers suit best for EVM. Fuzzy numbers respective to various linguistic terms given in Table 5

Table 5:Fuzzy Numbers for each Linguistic terms

\begin{tabular}{|l|c|}
\hline \multicolumn{1}{|c|}{$\begin{array}{c}\text { Linguistic } \\
\text { Terms }\end{array}$} & $\begin{array}{c}\text { Fuzzy Number } \\
\widetilde{\boldsymbol{F}}_{\boldsymbol{i}}=\left[\boldsymbol{a}_{\mathbf{1 i}}, \boldsymbol{a}_{\mathbf{2} \boldsymbol{i}}, \boldsymbol{a}_{\mathbf{3 i}}, \boldsymbol{a}_{\mathbf{4} \boldsymbol{i}}\right]\end{array}$ \\
\hline Very Low & {$[0,0,0.1,0.2]$} \\
\hline Low & {$[0.1,0.2,0.2,0.3]$} \\
\hline Less than Half & {$[0.2,0.3,0.4,0.5]$} \\
\hline Half & {$[0.4,0.5,0.5,0.6]$} \\
\hline More than Half & {$[0.5,0.6,0.7,0.8]$} \\
\hline High & {$[0.7,0.8,0.8,0.9]$} \\
\hline Very High & {$[0.8,0.9,1,1]$} \\
\hline
\end{tabular}

Next, fuzzy earned value $\left(\widetilde{E V}_{i}\right)$ of each activity is given in (14). The total fuzzy earned value $\widetilde{E V}$ is summation of fuzzy earned value of each activity as in (15).

$\widetilde{E V}_{i}=\tilde{F}_{i} \times B A C_{i}=\left[E_{1 i}, E_{2 i}, E_{3 i}, E_{4 i}\right]$

$\widetilde{E V}=\sum_{i=1}^{n} \widetilde{E V}_{i}=\sum_{i=1}^{n} E_{1 i} \sum_{i=1}^{n} E_{2 i} \sum_{i=1}^{n} E_{3 i} \sum_{i=1}^{n} E_{4 i}(15)$

With help of Fuzzy earned value $\left(\widetilde{E V}_{i}\right)$ the other parameters like cost performance index, schedule performance index, critical ratio, earned schedule, estimate at completion and schedule at completion as mentioned inTable 6 .

Table 6: Fuzzy Parameters and Formulae

\begin{tabular}{|l|l|}
\hline Parameter & Formula \\
\hline $\begin{array}{l}\text { Schedule } \\
\text { PerformanceIndex }\end{array}$ & $\widetilde{S P I}=\frac{\widetilde{E V}}{P V}$ \\
\hline
\end{tabular}

\begin{tabular}{|l|c|}
\hline $\begin{array}{l}\text { Cost Performance } \\
\text { Index }\end{array}$ & $\widetilde{C P I}=\frac{\widetilde{E V}}{A C}$ \\
\hline $\begin{array}{l}\text { Critical Ratio } \\
\text { Earned Schedule }\end{array}$ & $\widetilde{E S}=A T+\frac{\widetilde{E P} I \times \widetilde{C P I}-P V_{n}}{P V_{n+1}-P V_{n}}$ \\
\hline $\begin{array}{l}\text { Estimate at Completion } \\
\text { Time Estimate at }\end{array}$ & $\widetilde{E A C}=\frac{B A C}{\widetilde{C P I}}$ \\
\hline \begin{tabular}{l} 
Completion \\
\hline
\end{tabular}
\end{tabular}

Integrating the fuzzy principles with the Earned Value calculations doesn't have the limits of the deterministic Earned Value models and it can predict the project statuecloser to the reality[16].

\subsection{Earned Value Method with Grey Theory}

Data from ongoing projects for updating master schedule often suffers from uncertainty. In many cases, definingearned value of the activities is practically impossible due to immeasurable nature and requires significant effort.Project failures may occur due to ignoring these uncertainties. This can be eliminated by integrating grey theory into EVM[17].

Grey EVM best suits for updating the projectschedules having poor information regarding activities performance[18]. Grey theory converts linguistic terms into grey numbers by defining its possible upper and lower limits. Then by applying various formulas, monitoring parameters can be found out.

Firstly, progress of each activity needs to define in terms of linguistic terms and then convert those linguistic terms into grey numbers based on the distribution considered by the estimator. In general,grey numbers for linguistic terms are given inTable 7.

Table 7:Grey numbers for Linguistic Terms

\begin{tabular}{|l|c|}
\hline \multicolumn{1}{|c|}{ Linguistic Terms } & $\begin{array}{c}\text { Grey Number } \\
\otimes A=[\underline{\mathbf{m i n}}, \overline{\mathbf{m a x}}]\end{array}$ \\
\hline Very Low & {$[\underline{\mathbf{0 . 0}}, \overline{\mathbf{0 . 1}}]$} \\
\hline Low & {$[\underline{\mathbf{0 . 1}}, \overline{\mathbf{0 . 3}}]$} \\
\hline Less than Half & {$[\underline{\mathbf{0 . 3}}, \overline{\mathbf{0 . 4}}]$} \\
\hline Half & {$[\underline{\mathbf{0 . 4}}, \overline{\mathbf{0 . 5}}]$} \\
\hline More than Half & {$[\underline{\mathbf{0 . 5}}, \overline{\mathbf{0 . 6}}]$} \\
\hline High & {$[\underline{\mathbf{0 . 6}}, \overline{\mathbf{0 . 9}}]$} \\
\hline Very High & {$[\underline{\mathbf{0 . 9}}, \overline{\mathbf{1 . 0}}]$} \\
\hline
\end{tabular}


Chitti Babu Kapuganti et al., International Journal of Emerging Trends in Engineering Research, 8(10), October 2020, 7540 - 7547

Grey Earned value of each activity is find out by multiplying budget at completion of each activity and grey number of percentage completion as shown in(16). The greyearned value of project is found out by summation of minimum and maximum values of each activity earned values separately as in (17).

$$
\begin{aligned}
& \otimes E V_{i}=\otimes A_{i} \times B A C_{i}=\left[B A C_{i} \times \underline{A_{i}}, B A C_{i} \times \overline{A_{i}}\right] \\
& 16 \\
& \otimes E V=\sum_{i=1}^{n} \otimes E V_{i}=\left[\sum_{i=1}^{n} \underline{E V_{i}}, \sum_{i=1}^{n} \overline{E V_{i}}\right]
\end{aligned}
$$

Grey earned value calculations requires very less amount of information regarding activities and considers uncertainties in the data. This makes an advantage for calculating further performance indicators based on earned value.Grey performance indices, grey cost estimate at completion andgrey time estimate at completion are given inTable 8 .

Table 8: Grey Parameters and Formulae

\begin{tabular}{|l|c|}
\hline Parameter & Formula \\
\hline $\begin{array}{l}\text { Schedule } \\
\text { PerformanceIndex }\end{array}$ & $\bigotimes S P I=\frac{\otimes E V}{P V}$ \\
\hline $\begin{array}{l}\text { Cost Performance } \\
\text { Index }\end{array}$ & $\otimes C P I=\frac{\otimes E V}{A C}$ \\
\hline $\begin{array}{l}\text { Critical Ratio } \\
\text { Earned Schedule }\end{array}$ & $\otimes E S=Q S P I \times \otimes C P I$ \\
\hline $\begin{array}{l}\text { Estimate } \\
\text { Completion }\end{array}$ & $\otimes E A C=\frac{B A C}{P V_{n+1}-P V_{n}}$ \\
\hline $\begin{array}{l}\text { Time Estimate at } \\
\text { Completion }\end{array}$ & $\bigotimes E A C_{t}$ \\
& $=A D+\frac{P D-\otimes E S}{\otimes S P I}$ \\
\hline
\end{tabular}

Exact control over project requires accurate data, but the accurate measurement of project progress is exceptionally difficult, if not impossible. Grey EVM gives the performanceparameters in terms of grey numbers. It directly gives the maximum and minimum values of parameters [19-23].

\section{CONCLUSIONS}

Earned value management is one of the most utilized project monitoring and controlling techniques. It is simple to use and very informative to top-level management. In spite of simplicity, EVM is primarily developed as a cost management tool which lacks in development of accurate time estimate at completion. Various extensions developed to overcome these difficulties. These extensions have been discussed in this paper. Deterministic approaches will improve forecasting accuracy but lacks in stating the limits of maximum and minimum possible estimates at completion.

\section{REFERENCES}

1. W. fleming Quentin and M. K. Joel, Earned Value Project Management, Fourth Edition, vol. 17, no. 1. 2010.

2. J. Colin and M. Vanhoucke, "A comparison of the performance of various project control methods using earned value management systems," Expert Syst. Appl., vol. 42, no. 6, pp. 3159-3175, 2015, doi: 10.1016/j.eswa.2014.12.007.

3. H. L. Chen, W. T. Chen, and Y. L. Lin, "Earned value project management: Improving the predictive power of planned value," Int. J. Proj. Manag., vol. 34, no. 1, pp. 22-29, 2016, doi: 10.1016/j.ijproman.2015.09.008.

4. S. Sackey, D. E. Lee, and B. S. Kim, "Duration Estimate at Completion: Improving Earned Value Management Forecasting Accuracy," KSCE J. Civ. Eng., vol. 24, no. 3, pp. 693-702, 2020, doi: 10.1007/s12205-020-0407-5.

5. De Marco and T. Narbaev, "Earned value-based performance monitoring of facility construction projects," J. Facil. Manag., vol. 11, no. 1, pp. 69-80, 2013, doi: 10.1108/14725961311301475.

6. W. Lipke, "Examining Project Duration Forecasting Reliability," PM World J., vol. III, no. III, pp. 1-10, 2014, [Online]. Available: http://pmworldjournal.net/wpcontent/uploads/2014/03/pmwj20-mar2014-lipkeexamining-project-duration-forecastingFeaturedPaper.pdf.

7. F. T. Anbari, "Earned value project management method and extensions," IEEE Eng. Manag. Rev., vol. 32, no. 3, pp. 97-110, 2004, doi: 10.1109/EMR.2004.25113.

8. W. Lipke, "Schedule Is Different," Meas. News, vol. 2, no. March \& Summer, p. 93, 2003.

9. W. Lipke, "Schedule adherence and rework," CrossTalk, vol. 25, no. 6, pp. 4-8, 2012.

10. R. Elshaer, "Impact of sensitivity information on the prediction of project's duration using earned schedule method," Int. J. Proj. Manag., vol. 31, no. 4, pp. 579588, 2013, doi: 10.1016/j.ijproman.2012.10.006.

11. H. Khamooshi and H. Golafshani, "EDM: Earned Duration Management, a new approach to schedule performance management and measurement," Int. J. Proj. Manag., vol. 32, no. 6, pp. 1019-1041, 2014, doi: 10.1016/j.ijproman.2013.11.002.

12. C. Kim and K. F. Reinschmidt, "Probabilistic forecasting of project duration using bayesian inference and the beta distribution," J. Constr. Eng. Manag., vol. 135, no. 3, pp. 178-186, 2009, doi: 10.1061/(ASCE)0733-9364(2009)135:3(178).

13. G. A. Barraza, F. Mata, and W. E. Back, "PROBABILISTIC MONITORING OF PROJECT PERFORMANCE USING SS-CURVES,” vol. 126, no. April, pp. 1-15, 2014, doi: 10.1057/jibs.2014.26.

14. Ghanbari, H. Taghizadeh, and S. Iranzadeh, "Project Duration Performance Measurement By Fuzzy Approach Under Uncertainty," Eur. J. Pure Appl. Math., vol. 10, no. 5, pp. 1135-1147, 2017, [Online]. Available: www.ejpam.com.

15. L. M. Naeni, S. Shadrokh, and A. Salehipour, "A fuzzy approach for the earned value management," Int. J. Proj. Manag., vol. 29, no. 6, pp. 764-772, 2011, doi: 10.1016/j.ijproman.2010.07.012. 
16. J. L. Ponz-Tienda, E. Pellicer, and V. Yepes, "Complete fuzzy scheduling and fuzzy earned value management in construction projects," J. Zhejiang Univ. Sci. A, vol. 13, no. 1, pp. 56-68, 2012, doi: 10.1631/jzus.A1100160.

17. S. Hendiani, M. Bagherpour, A. Mahmoudi, and H. Liao, "Z-number based earned value management (ZEVM): A novel pragmatic contribution towards a possibilistic cost-duration assessment," Comput. Ind. Eng., vol. 143, p. 106430, 2020, doi: 10.1016/j.cie.2020.106430.

18. Mahmoudi, M. Bagherpour, and S. A. Javed, "Grey Earned Value Management: Theory and Applications," IEEE Trans. Eng. Manag., pp. 1-19, 2019, doi: 10.1109/TEM.2019.2920904.

19. Kumar, C.S., Kapuganti, C.B., Eswara Rao, S., Santhosh Kumar, T., Ramesh, B. Application of last planner system as lean construction technique, International Journal of Emerging Trends in Engineering Research, 2020, 8(9), pp. 6035-6041, 184

20. Kumar, T.S., Balaji, K.V.G.D., Ram, N.T., Kapuganti, C.B., Sowjanya, C.L. Effect on $\mathrm{CO} 2$ cured concrete exposed to sodium sulphate, International Journal of Emerging Trends in Engineering Research, 2020, 8(7), pp. 3670-3674

21. Kapuganti, C.B., Balaji, K.V.G.D., Santhosh Kumar, T., Comparison of project monitoring and controlling methods: Earned value management (EVM) \& earned duration management (EDM), International Journal of Recent Technology and Engineering, 2019, 7(6), pp. 549-555

22. Kapuganti, C.B., Kumar, P.Y., Teja, M.S., Akhil, A., Barbhuiya, R., Project schedule monitoring by earned duration management (EDM), International Journal of Recent Technology and Engineering, 2019, 7(6), pp. 518-522

23. Kumar, T.S., Balaji, K.V.G.D., Reddy, C.S., Babu, K.C., Sowjanya, C.L., Performance of co2 cured sugar cane bagasse ash concrete in marine environment, Civil Engineering and Architecture, 2020, 8(5), pp. 771-776 